\title{
ARGUEDAS: EL NARRADOR Y EL ANTROPOLOGO FRENTE AL LENGUAJE
}

\author{
POR \\ WILLIAM ROWE \\ University of London
}

Cualquier descripción de lo social en la obra de Arguedas se complica inmediatamente con la heterogeneidad de la sociedad andina, heterogeneidad que se da en términos de la historia y de los distintos modelos de interpretación. Se han utilizado dos formas de análisis principales: una que emplea conceptos de etnicidad y la otra que identifica los elementos de clase social y base económica. Las diferencias ocurren en varios niveles: como variaciones de autodefinición entre indios y no-indios (distinción que resulta problemática); como tipificación externa entre la antropología y el marxismo, y de una manera simultáneamente externa e interna, entre el lenguaje mítico y otros tipos de lenguaje. Mi propósito en este trabajo será ubicar la obra de Arguedas dentro del campo de estas diferencias y explorar los sentidos en que la obra también se encamina hacia una modificación del campo.

La base para la actitud etnológica está expresada en un artículo de Juan Ossio: "No creemos que el rechazo de los indígenas hacia los Mistis pueda explicarse por un sentimiento de clase explotada, sino del hecho que estos últimos son percibidos como ilegítimos o seres asociales que han disrupcionado el orden de los indígenas» ${ }^{1}$. Del otro lado, Montoya, Silveira y Lindoso se apoyan, en un estudio reciente del área de Puquio, en los conceptos marxistas de modos de producción y relaciones de producción, criticando la explicación étnica como cada vez menos viable: la oposición étnica disfraza la dominación de clase; las mismas palabras «mestizo», «criollo», «cholo» e «indio» esconden el problema

${ }^{1}$ Juan M. Ossio, «Relaciones interétnicas y verticalidad ecológica en la Comunidad de Andamarca», Actes du XLII ${ }^{e}$ Congrès International des Américanistes, vol. IV, p. 196. 
de clase social: «La representación de las relaciones sociales de clase a partir de elementos étnicos... tiene cada vez menos base» ${ }^{2}$. Montoya y sus coautores rechazan la concepción «culturalista» que percibe la sociedad andina como una relación entre dos culturas y contraponen un análisis del proceso productivo y las estructuras de clase ${ }^{3}$.

Las diferencias tipificadas por Ossio y Montoya se hacen sentir en toda la obra de Arguedas. Ya que tienen una figuración compleja, variando tanto entre lo literario y lo no literario como también al interior de estas categorías, intentaré trazar las líneas generales de la oposición.

Como antropólogo, Arguedas pone mayor énfasis en el aspecto cultural: un lenguaje de categorías culturales predomina sobre los elementos de análisis de clase. En la ficción, y especialmente en TS y EZ ${ }^{4}$, se presta más atención a relaciones económicas y de clase. Sin embargo, dentro de la obra literaria existe un conflicto entre lo mágico y lo político que queda excluido de los trabajos antropológicos. Mientras que «Agua» presenta una estratificación rígida entre los indios y la casta terrateniente, YF y RP se hacen progresivamente más culturales en cuanto a sus premisas, descubriendo en la cultura quechua un universo cada vez más autónomo. YF se desplaza ambiguamente entre el discurso mágico y el análisis de clase, y el rechazo de lo político llega a su culminación en ES, donde el lenguaje político queda marginado, marginación en alguna medida retrospectiva porque el lenguaje político de Escobar en YF es criticado mucho menos duramente que el de los líderes comunistas y apristas en ES, aunque este libro pertenece a la misma época en que Arguedas escribía YF.

La tendencia culturalista de la producción antropológica es ejemplificada por el estudio de Puquio. Este puede compararse con el trabajo de Montoya, puesto que, aun con las diferencias históricas (1950/ 1970), lo que describe Montoya debe de haber estado presente, al menos de una manera latente, cuando Arguedas hacía sus investigaciones de campo. Los cambios que descubre Arguedas en el Puquio de los cincuenta, comparado con el de su infancia, no los atribuye sino de modo

${ }^{2}$ Rodrigo Montoya, M. J. Silveira, F. J. Lindoso, Producción parcelaria y universo ideológico (Lima, 1979), pp. 14, 151, 159.

${ }^{3}$ Véase también Mirko Lauer, «Artesanía y capitalismo en el Perú»: «El encuentro ya no es hoy entre 'Occidente' y 'los Andes', sino de los valores del capitalismo dependiente con los del precapitalismo en el punto del encuentro del arte, la cultura y la economía», en Análisis (Lima, núm. 5), p. 20.

${ }^{4}$ Para referirse a las obras de Arguedas se han utilizado las siguientes siglas: $\mathrm{YF}=$ Yawar Fiesta, $\mathrm{DP}=$ Diamantes $y$ pedernales, $\mathrm{RP}=$ Los rios profundos, $\mathrm{ES}=E l$ Sexto, $\mathrm{TS}=$ Todas las sangres, $\mathrm{EZ}=E l$ zorro de arriba y el zorro de abajo. 
superficial a las fuerzas económicas, lo cual impide que emerja la función ideológica de la cultura indígena. Para expresar las perspectivas para el futuro se refiere a un posible retorno del héroe Inkarrí. Igualmente sostiene un pronóstico positivo para las comunidades del valle del Mantaro, precisamente porque arranca de una interpretación culturalista según la cual el mestizaje figura como solución. A fines de los años cincuenta y principios de los sesenta empezó a escribir sobre la inmigración hacia la costa, pero igualmente insiste en los factores culturales. De otro lado, los argumentos y. los factores históricos que contradicen la tesis culturalista emergen en TS y no, como podría esperarse, en los estudios antropológicos. Las instancias más importantes serían: la "penetración» del capitalismo en las áreas de la economía tradicional; el punto de vista de los mineros no-indígenas, que consideran que la actitud al trabajo de los comuneros (la costumbre de la faena) impide la conciencia de clase, y los discursos de Rendón Willka contra la religión. EZ es más complejo, pero por ahora puede decirse que introduce una cantidad de factores adicionales que reducen el alcance de la interpretación étnico-cultural: la tecnología, la lucha sindical, la corrupción capitalista (no hay capitalistas nacionalistas como don Fermín) y, desde luego, la inmigración masiva de quechua-hablantes a una cultura ajena.

De este modo, los trabajos antropológicos tienden a articular la idea que de sí mismos tienen los indígenas -o, para emplear el término de Wachtel, su visión, que, a pesar de crear una base para la resistencia, también permitió la dominación: porque no suministró una representación suficientemente exacta de las fuerzas del enemigo; o sea, en vez de desmitificar la ideología dominante, la traducía a otros mitos. Pero si limitaba el nivel en que la oposición podía articularse, respondía a la vez a los recursos materiales limitados, y desde este punto de vista servía para enfocar la resistencia. Desde un punto de vista epistemológico, la visión cultural de la población oprimida puede definirse entonces como una intersección compleja que combina dos grupos de oposiciones, culturales y sociales: entre lo occidental y lo andino y entre la clase dominante y la clase oprimida.

Para hacer un resumen de lo dicho hasta ahora: las implicaciones de lo social con relación a la obra de Arguedas incluyen en primer lugar una contradicción entre varios discursos referentes a la sociedad andina. Estos se tipifican en las diferencias entre categorías etnológicas y marxistas. En segundo lugar, el lenguaje que utiliza el campesinado indígena para caracterizarse es mítico y no político, pues lo político es utilizado por otros sectores más «modernizados». 
En lo que sigue propongo desarrollar los siguientes puntos: a) que los diferentes lenguajes se vinculan, mediante sus premisas ideológicas, con diferentes bases sociales, y $b$ ) que el área en que la obra de Arguedas tiene mayor proyección en su respuesta creadora a la heterogeneidad de la sociedad andina ( $y$ en realidad de la peruana) consiste en su entendimiento del mito y de la desmitificación como necesidades simultáneas ${ }^{5}$, lo cual hace difícil una síntesis.

\section{Los diferentes lenguajes de Arguedas}

Empezaré con YF, puesto que allí se destacan con más claridad ciertos problemas del lenguaje. YF tiene como proyecto la construcción de un idioma mestizo capaz de representar la aculturación mutua. La trama, sin embargo, se desplaza en la dirección opuesta, hacia la autonomía cultural de lo indígena. Del otro lado, el lenguaje que habla Escobar, ex comunero y estudiante socialista, introduce un elemento ajeno: cuando habla de la necesidad de eliminar «el temor mítico» para que los indios sean genuinamente liberados, está expresando una preocupación que se manifiesta en todas las novelas de Arguedas (pero no en los trabajos antropológicos), y hay que recalcar que lo hace en un lenguaje de tipo científico-analítico, cuyas implicaciones comentaré luego.

YF, publicado en 1941, ya estaba comenzado en 1937 (fecha de una primera versión del capítulo II). Entre estas dos fechas, en 1939, Arguedas empezó a escribir su primera serie de artículos sobre la cultura indígena, que fueron publicados en La Prensa de Buenos Aires entre 1939 y 1948. Al mismo tiempo fue a vivir a Sicuani y conoció al padre Lira. Estos artículos, donde Arguedas se presenta como el portavoz del folklore peruano, son significativos para el desarrollo de su lenguaje: en ellos se revela por primera vez el lenguaje de DP y de RP. Por ejemplo, existen muchas semejanzas entre la prosa de «El carnaval de Tambobamba», publicado en La Prensa en 1942, y «Los viajes», el capítu1o II de RP. Además, una primera versión del comienzo de Zumbayllu, el comentario sobre yllu e illa, apareció en La Prensa en 1948 como artículo sobre el folklore. Ese mismo año, en la revista Las Moradas, se publicó el primer fragmento de la novela. Entre YF y los primeros fragmentos de RP, Arguedas no había escrito obra de ficción, por 10 cual los artículos sobre el folklore representan su labor en el lenguaje.

${ }^{5}$ Sería apropiado recordar aquí el concepto que tuvo Mariátegui de la necesidad del mito para una política socialista en el Perú. 
El principio crucial de RP es el de la traducción, tanto del idioma como de la cultura. En el ensayo La novela y el problema de la expresión literaria en el Perú (1953) habla de la opción de la traducción. Su actitud anterior está delineada en «Entre el kechwa y el castellano», primer artículo de la serie de La Prensa. Allí describe el estilo de la «mixtura", o sea, el de YF, como el único medio literario apropiado para los mestizos, entre los que se incluye a sí mismo. La "mixtura», como él lo llama, tiene como intención la representación de la síntesis, pero cotejada con las relaciones sociales reales en el Perú solamente se refiere a una tierra de nadie no existente y que no corresponde a la praxis social de ningún grupo - justamente por eso, la trama, como expresión de lo práctico, está en conflicto con el lenguaje-. También asevera que este lenguaje es natural, justificación que no necesitaría para DP o RP, donde se reconoce plenamente la primacía de la invención literaria.

La traducción, que en cierto nivel significa trasladar lo indígena al otro idioma, representa a un nivel más profundo la apropiación del idioma más universal por lo indígena. Como dice Wachtel, «la dinámica de la aculturación es inseparable de la acción creadora de una praxis que reestructura los rasgos prestados en respuesta a una situación histórica» ${ }^{\text {. }}$ O sea, que cualquier noción de la aculturación o de la "transculturación» (palabra quizá demasiado inocente) depende de una manera decisiva de la praxis que la dirige. Como demuestra Julio Ortega, el mestizaje tiende a sobrevaluarse: dada la pluralidad de la cultura peruana, "no se puede decidir una aculturación simétrica que produzca una síntesis elaborada como 'mestiza'». Mientras que la otra versión del mestizaje, la de la incorporación de las minorías a la cultura nacional, es «un mestizaje sobreimpuesto» y «nivelador»; porque el intercambio cultural tiene lugar dentro de un régimen de dominación ${ }^{7}$. El mestizaje mutuo y simétrico de YF, ya que deja al lado las relaciones de poder, resulta una mezcla inestable y abstracta, de la cual las ambigüedades se atestiguan en los repetidos intentos de Arguedas para resolver los problemas del lenguaje en esa novela.

El lenguaje de YF no llega a concretar lo que promete porque trata la aculturación como un proceso acumulativo y cuantitativo: la técnica de la «mixtura» consiste en trasladar unidades aisladas del quechua al castellano, cuando la cultura, como el idioma, es un sistema integral, principio que del otro lado está reconocido por la trama.

\footnotetext{
' Nathan Wachtel, The Vision of the Vanquished (Sussex, 1977), p. 209.

${ }^{7}$ Julio Ortega, «Crisis, identidad y cultura en el Perú», en Perú: Identidad nacional (Lima, 1979), pp. 199, 200.
} 
Como antropólogo profesional, Arguedas tiene otro lenguaje. En los escritos antropológicos, que comienzan en la década de los cincuenta, se introduce una distancia que no figura en los trabajos anteriores, como los de La Prensa de Buenos Aires. La valoración del lenguaje científico excluye, por ejemplo, la participación en la magia. Esto apunta hacia una equivalencia con el lenguaje político: en el discurso «No soy un aculturado», Arguedas declara que el socialismo «no mató en mí lo mágico» - cosa que sí le pasó a Escobar-. Sin embargo, al final del estudio sobre Puquio, cuando quiere referirse a la totalidad e incluir las perspectivas para el futuro, recurre al mito: «Inkarrí vuelve». Los mitos mesiánicos tienen como función crucial la colocación de la cultura quechua dentro de lo político mediante la resurrección del concepto de un sistema estatal indígena. El porqué la mitología se haga necesaria en este sentido es un problema al que volveré más tarde. Por ahora se puede decir que, para la antropología, el mito viene a ser una forma legítima para la política andina, porque preserva el parámetro étnico y es capaz de dar una proyección nacionalista a la etnicidad.

\section{LA MAGIA Y LA POLÍTICA}

Antes de considerar en más detalle las relaciones entre lo mágico y lo político habría que indicar la complejidad del contexto y demostrar lo inadecuado de un análisis puramente literario del lenguaje de Arguedas. La cita que sigue es del capítulo II de RP:

Ya debía amanecer. Habíamos llegado a la región de los lambras, de los molles y de los árboles de tara. Bruscamente, del abra en que nace el torrente salió una luz que nos iluminó por la espalda. Era una estrella más luminosa y helada que la luna. Cuando cayó la luz en la quebrada, las hojas de los lambras brillaron como la nieve; los árboles y las yerbas parecían témpanos rígidos; el aire mismo adquirió una especie de sólida transparencia. Mi corazón latía como dentro de una cavidad luminosa ${ }^{8}$.

Se necesitan al menos tres formas de análisis. En primer lugar, en cuanto a las formas literarias, no se trata del lirismo romántico, o sea, no es cuestión de la mente individual que descubre una compenetración con la naturaleza. Después, esta visión está apuntalada por una concepción del cosmos, según la cual la estrella y la conciencia interior

${ }^{3}$ Buenos Aires, Losada, 1958, p. 35. 
pertenecen a una misma continuidad: o sea, tenemos un caso del fisiomorfismo del hombre. Se trata también, en términos contextuales, de estructuras sociales precapitalistas y del universo épico que describe Lukács en La teoría de la novela. Y si, como dice Lukács, las estrellas son los caminos de los hombres, entonces existe al mismo tiempo la unidad de lo físico y lo semántico, que convierte las propiedades sensibles de la naturaleza en los elementos de un mensaje?

La acción de rebelión social más importante en RP - la entrada de los colonos en la ciudad - se resuelve a un nivel mágico, mientras que el nivel político solamente se articula fuera de la novela, por ejemplo, en los comentarios de Arguedas en el Primer encuentro de narradores peruanos ${ }^{10}$. Dentro de la novela, la acción mágica permanece condicional y dependiente de la visión de Ernesto: «La peste estaría, en ese instante, aterida por la oración de los indios...» (el subrayado es mío) ${ }^{11}$. Por el contrario, en TS lo mágico deja de ser condicional o dependiente de la sensibilidad de un niño, y lo político se sitúa adentro, aumentando, como consecuencia, las contradicciones.

El principio de que el mito puede expresar el pensamiento político y que esto es una característica de la cultura andina ha sido ampliamente demostrado en un buen número de libros que han aparecido en los últimos diez años, como, por ejemplo, De Adaneva a Inkarrí, de Alejandro Ortiz; El Dios Creador andino, de Franklin Pease; Ideología mesiánica del mundo andino, de Juan Ossio, y La vision des vaincus, de Nathan Wachtel. En TS, los mitos y la ideología se entrecruzan y los sucesos mágicos comentan el significado de las acciones sociales. Históricamente, una vez que el campesinado recurre al lenguaje político, ya no vuelve al lenguaje mágico, aunque sí puede ocurrir que la forma moderna-política conserve un contenido andino-tradicional, religioso. Sin embargo, hay en la novela un fenómeno que, según entiendo, no se da entre el campesinado: se utiliza el pensamiento mágico para apoyar a ideologías que no tienen su origen en la cultura andina. Más específicamente, se emplea una significación mágica (como la aparición de los pájaros, por citar un ejemplo) no sólo para articular contenidos étnicos, sino para justificar praxis e ideas políticas que vienen de afuera, lo que convierte la magia en una especie de coartada. Tal maniobra se asemeja a la retórica del indigenismo, especialmente cuando éste toma la forma del populismo andino. El Apra y más tarde Acción Popular

\footnotetext{
${ }^{9}$ Véase C. Lévi-Strauss, The Savage Mind (Londres; 1972), p. 268.

${ }^{10}$ Primer Encuentro de Narradores Peruanos (Lima; 1969), p. 239.

${ }^{11}$ RP, p. 247.
} 
y el reciente Gobierno Militar (primera fase) crearon una retórica andina o incaica para la incorporación de nuevas áreas en el capitalismo. La «planificación incaica» de Acción Popular legitimaba la creación de una infraestructura para acelerar y legitimar esta incorporación ${ }^{12}$; el indigenismo de la década del treinta suministraba una versión bucólica de las aspiraciones pequeño-burguesas.

El disfraz ideológico otorgado por el mito tiene su paralelo en la adopción del ayllu como modelo del cripto-capitalismo: uno de los primeros ejemplos sería esta afirmación de Haya de la Torre en El antiimperialismo y el Apra: "Intensificada la producción, organizada sobre la base de la restauración de la comunidad agraria, evolucionada, modernizada, impulsada con todos los elementos de la técnica moderna y organizada cooperativamente, Indoamérica será el granero y el establo del mundo» ${ }^{13}$. Montoya, refiriéndose a Puquio en los años setenta, señala cómo el ayllu puede servir de coartada para estructuras capitalistas: «La institución comunal tiende a enmascarar la situación de clase bajo el igualamiento general, en base a la condición de comuneros» ${ }^{14}$.

Pero hay una diferencia fundamental entre el indigenismo y el lenguaje de Arguedas en TS: la presencia de la magia en éste es demasiado subversiva para ser asimilada por el indigenismo. Ciro Alegría naturaliza las creencias mágicas, presentándolas como supersticiones; Arguedas revela su aspecto transformador. Esto puede verse, por ejemplo, en las acciones mágicas del danzante Tankayllu, que corresponden a las propiedades del zumbayllu; o en el personaje Diego, de EZ, a quien se han dado (como demuestra Martin Lienhard) varios de los atributos del danzante.

Rendón Willka, en el discurso final a los ex colonos de La Providencia, relaciona la liberación en el presente con un retorno al pasado:

Los gendarmes van a venir quizá mañana, quizá dentro de tres días, y van a querer apagar el sol. ¿Pueden apagar el sol? No pueden apagarlo. Así tampoco nos quitarán la tierra. Que cada hombre muera en el sitio que la hacienda le ha señalado para que trabaje. La hacienda es del padre Pukasira. El hizo esta tierra antes de que los señores werak'ochas hubieran llegado a nuestros pueblos. Los werak'ochas no sabemos de dónde vinieron, y por la fuerza se agarraron nuestras tierras ${ }^{15}$.

${ }^{12}$ Véase Sebastián Salazar Bondy, «La evolución del llamado indigenismo», Sur, marzo-abril 1965, p. 48.

${ }^{13}$ Lima, s. f. (2." edición), pp. 180-181.

${ }_{14}$ Montoya, p. 94.

${ }_{15}$ TS (Losada, 1964), p. 464. 
Ese «no sabemos de dónde vinieron» es la voz de la experiencia precolombina de la conquista y vuelve a un concepto precolombino de la autonomía. Pero el hecho de que Rendón articule un mito del retorno no garantiza una dedicación a una praxis revolucionaria. El lado práctico de su programa se absorbe dentro de estructuras capitalistas, y solamente en la imaginación va más lejos. Un mito del retorno al pasado puede carecer, específicamente, de una respuesta al presente suficientemente creadora. ¿En qué medida utiliza Rendón el mito y el símbolo, capaces de almacenar el pasado, pero no de cambiarlo, en lugar del análisis y la praxis?

Los trabajadores comunistas y apristas introducen conceptos de la explotación de clase y de la distribución desigual de la plusvalía; Rendón apela a la igualdad en el trabajo y así desvía la atención sobre la distribución desigual del producto. Montoya encuentra en Puquio el mismo fenómeno; éste representa la reproducción de una estructura que viene desde los principios de la época colonial: la modificación, por los españoles, del sistema inca de reciprocidad y redistribución. Cuando habla de la tierra, Rendón parece querer unir una actitud tradicional andina con la ideología no andina del nacionalismo populista: «Wisther, ¿no ha de morir algún día, don Antenor? Yo no voy a morir. En mi tierra estoy; en mi tierra ha salido el metal» ${ }^{16}$. ¿La opacidad se debe a un deseo de ser enigmático (como parece ser el caso cuando Rendón habla con Cabrejos)? En realidad, tal efecto, el de enturbiar el habla, además de ser una manera tradicional de tratar con el opresor, es también el resultado del encuentro entre dos tipos de discurso, el mágico y el político, como queda claro en el caso de Diego en EZ.

\section{El PROBlema DE LA SÍNTESIS}

Para encontrar una respuesta adecuada a la sociedad capitalista, los indígenas necesitarán entonces una política de origen no andino: ¿qué sucederá entonces con el mito? Rendón utiliza tanto el discurso mítico como (aunque menos frecuentemente) un discurso político y científico, revelando una serie de discordancias cuyas implicaciones son complejas. Rendón invierte lo que ocurre con el campesinado (un lenguaje de forma política pero de contenido religioso) y utiliza formas religiosas con un contenido político. Esto implica una estrategia consciente de síntesis y una utilización de lo religioso ya no «inocente». En otros momentos

16 TS, p. 285. 
apela a la secularización, rechazando el discurso mítico, como ocurre en el poema «Oda al jet». En un nivel práctico, el incidente del Amaru tiene el mismo sentido: como la captura del toro en YF, se trata de recuperar las energías atrapadas en los temores proyectados. Por eso Rendón apunta hacia una síntesis, para lograr la cual tendrían que transformarse tanto lo tradicional-andino como lo moderno-secular, acortando así la distancia entre los dos lenguajes.

Mientras tanto, hasta que se construya históricamente la síntesis, contenidos andinos como las relaciones sociales de ayuda mutua y la rica tradición cultural permanecen inseparables de formas de pensar míticas - esto es, hasta que lo moderno-occidental se transforme también-. Mientras tanto, el lenguaje del mito viene a ser una intersección entre lo que todavía puede llamarse indígena y lo que no lo es. Es por eso que, en la visión del propio Arguedas, los dioses todavía son necesarios para que haya un orden creador: esto se ve tanto en el estudio de $\mathrm{Pu}$ quio como en la «Oda al jet».

Arguedas no utiliza el mito para construir una coartada ahistórica, sino como principio desestructurante en oposición a estructuras sociales contemporáneas. Aceptar el lenguaje mítico, en este sentido, implica tomar lo precolombino como contemporáneo, contra las coartadas eurocéntricas y lineal-evolucionarias. Sigue siendo una sustitución de la imaginación por el análisis y la praxis, como se ve claramente en los episodios finales de YF, RP y TS. Del otro lado, habría que reconocer que permanecer dentro de los mitos significa responder a la dificultad de llegar a una praxis adecuada en la realidad -en este sentido, el mito es lo que Wachtel, partiendo de Marx, llama "praxis imaginaria»-. Así, el mito viene a ser una perpetuación del pasado como estático, almacenado, realidad a la cual siempre se retorna. En esta categoría se incluye, para Arguedas, la propia niñez. Como ha expuesto Cornejo Polar, «el aislamiento del mundo indio y la consecuente conservación de su índole, como realidad que tenazmente se aferra a sus propios modelos, representaba para Arguedas la opción del recuerdo personal y la posibilidad de saber que existía un mundo que no le era ajeno. La interacción de la sierra y la costa, el proceso de cambio del mundo andino y las transformaciones de la realidad indígena dejan a Arguedas sin ese recaudo íntimo: $\sin$ su infancia y sin su mundo ${ }^{17}$. EZ, libro que surge de esta interacción de costa y sierra y que también la pone en práctica, refleja tanto la pérdida de la niñez como modelo epistemológico como la crisis del lenguaje mítico.

\footnotetext{
${ }^{17}$ Los universos narrativos de José María Arguedas (Losada, 1973), p. 259.
} 
EZ es el libro más complejo de Arguedas. Las interacciones de costa y sierra son más variadas y múltiples, las transformaciones mutuas más sutiles; en el campo del lenguaje no hay jerarquías. Debido a la crisis del universo mitológico, el pensamiento mágico se fragmenta; cuando el sistema se desestructura, la magia se dispersa. Pero los resultados de la fragmentación no son necesariamente negativos, ocasionando una pérdida del poder y de la relevancia: por el contrario, la disgregación puede permitir que la magia penetre en todas partes, como en la canción de Paula Melchora:
Culebra Tinoco
culebra Chimbote
culebra asfalto
culebra Zavala
culebra Braschi
cerro arena culebra
juábrica harina culebra
challwa pejerrey, anchovita, culebra,
carritera culebra
camino de bolichera en la mar, culebra,
fila alcatraz, fila huanay culebra ${ }^{18}$.

La culebra es el amaru andino, significando el mundo de abajo ${ }^{19}$, que en este caso representa tanto el mundo debajo de la superficie (depósito de los dioses almacenados) como el mundo de la costa. Significa además el cambio (el nombre Túpac Amaru es un signo del cambio). La canción, por tanto, hace referencia a un pachacuti, una inversión o revolución del mundo ${ }^{20}$. Se invierte a la vez el concepto de la "penetración capitalista»: lo que es penetrado es el mismo capitalismo (las connotaciones sexuales-invasoras de la aculturación son tema principal). Al invertir la dirección de la aculturación se subvierte la premisa eurocéntrica normal de la aculturación.

Por primera vez en Arguedas el proceso de la producción capitalista es enfrentado y dilucidado directamente por el pensamiento mágico. TS interpreta al capitalismo ( $\mathrm{y}$ a la sociedad costeña) mediante modelos mecánicos: la terminología se deriva del marxismo; la actitud literaria, del naturalismo. El lenguaje naturalista conceptualiza un modelo socio-

${ }^{18}$ EZ (Losada, 1971), p. 58.

19 Véase Juan Ossio, «El simbolismo del agua y la representación del tiempo y el espacio en la fiesta de la acequia de la Comunidad de Andamarca», Actes du $\mathrm{XLII}^{\circ}$ Congrès International des Américanistes, vol. IV, p. 380.

${ }^{20}$ Debo esta aclaración a Alejandro Ortiz Rescaniere. 
económico que funciona coherentemente, punto de vista que se destroza en EZ. La cultura del Perú capitalista se analiza y se desarma, proceso que los zorros en su diálogo atribuyen a «la palabra»: «La palabra, pues, tiene que desmenuzar el mundo... El canto del pato de altura nos hace entender todo el ánimo del mundo» ${ }^{21}$. Se contrapone el lenguaje oral, mítico (el de la naturaleza, que unifica lo físico y lo semántico), y el escrito, no mítico. A la vez se disminuye la distancia entre los dos lenguajes: el cosmos mitológico se hace más verbal, o sea, más cerca al lenguaje de signos arbitrarios. $\mathrm{Y}$ del otro lado, el mundo costeño se abre hacia el universo mitológico; la presentación no lineal y no naturalista se entronca con el sistema de múltiple analogía del pensamiento mítico.

Los elementos míticos de $\mathrm{EZ}$ son mayormente no ideológicos, ya que no invocan una autonomía precolombina ni apelan al ayllu como modelo ni recomiendan el populismo nacionalista. Especialmente, la danza y la magia de Diego no son ideológicos. Ya no hay un discurso mítico como tal, sino la fuerza penetrante/subversiva de la cultura andina. Del mismo modo que la forma de hablar de Moncada lleva a una intensificación no ideológica de las contradicciones. Moncada rechaza las ideas del brujo de Esteban por ser «antiguallas». Interpreta a Chimbote en términos de jerarquías de clase y del capitalismo dependiente; contestando a Esteban, que habla de la mariposa como «mensajero», dice: «iNo hay mensajero de nada, compadre!... La muerte en el Perú patria es extranjero... La vida también es extranjero" ${ }^{22}$. Moncada representa una manera de entender que no se apoya en lo mágico-religioso. Al capitalismo lo interpreta como una borrachera universal que se posesiona de las mentes. Esta es la magia irracional del capitalismo, que la «locura» de Moncada le permite ver. El concepto de la magia se ha relativizado y ya no es privativo de lo andino.

La tendencia anti-religiosa es constante en Arguedas, aunque al final deja una voz importante a la religión. Pero, por así decirlo, «mientras tanto». Apuntan más allá de la religión el intento de Cardoso de desmitificar el concepto del cielo, como también la cita de San Pablo: «Ahora vemos las cosas en forma confusa, como reflejos borrosos en un espejo; pero entonces las veremos con toda claridad» ${ }^{23}$. Se aspira a la posibilidad de sobrepasar la necesidad de los símbolos.

La magia llega a ser, en último caso, la intersección de dos escalas

\footnotetext{
${ }^{21} \mathrm{EZ}$, p. 60.

22 EZ, p. 165.

${ }^{23}$ EZ, p. 280.
} 
temporales. En primer lugar, la de la universalización de los valores y la cultura andina, hasta ahora asociados con lo mágico-religioso debido a la no transformación de la cultura y el lenguaje opresores. Segundo, la de la transformación del sistema opresor, hasta ahora no llevada a cabo y todavía concebida, desde la cultura indígena, en términos míticos, o sea, como praxis imaginaria. La limitación política del mito de Inkarrí y de otros parecidos sería que tienen el propósito no tanto de transformar el sistema, sino de eliminarlo completamente y desde criterios étnicos. Quizá por eso han atraído a los antropólogos de la misma manera que las ideologías étnicas se hicieron populares en las dos últimas décadas por ser imágenes utópicas del cambio y formas de escaparse del sistema. $O$ bien invierten las jerarquías sociales en vez de eliminarlas $y$ transformarlas. $Y$ cuando esto se intenta en TS, se hacen patentes las contradicciones. Estos tipos de mito, como reconoce Arguedas al final del estudio de Puquio, preservan a los indígenas y su cultura, protegiéndolos de la desintegración y prometiendo la reintegración, sin ofrecer un método para cambiar la cultura opuesta. A medida que la respuesta andina se desplaza desde una praxis imaginaria a una praxis real y las fronteras entre los dos mundos desaparecen, el universo mitológico entra en crisis, mientras que la cultura del Perú capitalista pierde su apariencia monolítica e impenetrable. A despecho de la utilización del mito, la magia y el simbolismo religioso, pero también debido a su utilización, la obra de Arguedas atestigua la necesidad de ir más allá de la mitología. 
